\title{
EFFECT OF GRADATION OF AGGREGATES ON MARSHALL PROPERTIES OF SDBC MIX DESIGN
}

\author{
Deepesh Kumar Singh Lodhi' ${ }^{1}$, R. K. Yadav ${ }^{2}$ \\ ${ }^{I}$ Student, M.E. Geo-Technical Engineering, Department of Civil Engineering, Jabalpur Engineering College \\ Jabalpur, India \\ ${ }^{2}$ Associate Professor, Department of Civil Engineering College Jabalpur, India.
}

\begin{abstract}
Semi Dense Bituminous concrete (SDBC) is the upper bituminous layer of the road subjected to moderate traffic loads. The grading of aggregates used to prepare the SDBC mix should fall within the limits specified in MoRTH. For each aggregate fraction there is a specified gradation range with lower and higher limits of aggregates passing through a particular sieve size. The gradation range specified in MoRTH is quite wide. Therefore mix design by adopting a particular gradation of the aggregate falling within the MoRTH range also affects the Marshall properties. The present study is taken to evaluate the Marshall property of SDBC mix prepared using the aggregate having different grading within the grading limits specified by the MoRTH. In order to study this aspect five mixes having different gradation were prepared. The gradation used correspond to Lower Grade (L.G.), Lower Middle Grade (L.M.G.), Middle Grade (M.G.), Higher Middle Grade (H.M.G.), Higher Grade (H.G.) of the gradation range specified by MoRTH. The test result revealed that there is significant variation in Marshall Properties of the mixes having different gradation of the aggregates. The Stability values obtained is maximum for the Lower Middle Grade (L.M.G.) range of MoRTH specification. The Flow values obtained is maximum for the Middle Grade (M.G.).The Optimum Bitumen Content (O.B.C.) is also minimum in Lower Middle Grade (L.M.G.).
\end{abstract}

Keywords: Aggregate Gradation, Semi Dense Bitumen Concrete, Marshall Properties, Morth.

\section{INTRODUCTION}

Now a day's road transportation plays important role in development of any country. Due to this finding the best design of surfacing layer had been a positive competition among manufactures and designers. India has a road network of over 4.69 million kilometers, second large roadways in the world. Highway can be divided into two groups functionally and structurally. Functional classification further classified into five more categories as National Highways, State Highways, Major District Road, Other district roads, Village Road. Based on Structural performance, pavements can be classified into two types - Rigid and Flexible. Flexible pavements are those which are surface with bituminous materials. On the other hand Rigid pavements are composed of pre-stress cement concrete (P.C.C.). Most of the Indian roads are flexible pavements. SDBC mix is a heterogeneous material that consists of aggregate, filler, bitumen binder, stone dust and air voids. The particle size distribution, or gradation, of aggregates is most important factor that affects the whole performs of the pavement material. Gradation is one of most influence factors for Marshall Properties of SDBC mix, so it required to select best aggregates gradation. The best gradation is that gradation of aggregates which gives the highest density. When fine particles are properly packed between coarser particles, which reduces the voids space between particles is called as Best gradation. In the present study five gradation Lower Grade (L.G.).,Lower Middle Grade (L.M.G.), Middle Grade (M.G.), Higher Middle Grade (H.M.G.), Higher Grade (H.G.) were used within the range specified by Ministry of Road Transport and Highways
(MoRTH) at 4.5\%, 5\%, 5.5\% bitumen content, Marshall mixes were prepared and tested for its properties.

\section{BACKGROUND LITERATURE}

Vaniyapurackal et al. (2015) reported that for economy considering minimum percent bitumen content with maximum stability, bulk density and optimum flow the most suitable shape of aggregate appears to be cubical through our experimental study. P. Sarika et al. (2015) reported that MORTH lower gradation trial present the best result compared to the upper and middle gradations trials and the Superpave gradation can be considered as more economical than the MoRTH gradation due less binder content consumption and more stability. Mohamed Ilyas Anjum (2013) the obtained Marshall test properties fall within the MoRTH specifications for both SDBC and BC mixes at mid point gradation, with flow values exceeding the limit. Roberts et al. (1996) suggested that gradation is the most important property of bitumen mixes which affects properties of a bituminous mixture such as stiffness, stability, durability, workability, fatigue resistance, permeability, frictional resistance, and resistance to moisture damage. Afaf A.H.M. (2014) reported that course gradation of asphalt mixture design gives superior results against flow while fine gradation has the highest amount of deformation. Arijit Kumar Banerji et al. (2014) reported that variation in aggregate gradation within the specified limits can affect the essential mix design properties of bituminous mix. Ahlrich (1996) also reported that aggregate characteristics and gradations highly affected properties of Hot mix Asphalt. 


\section{MATERIALS USED}

\subsection{Bitumen:-}

Bitumen binders used in pavement construction works include both bitumen and tar. Bitumen is a petroleum product obtained by the distillation of petroleum crude whereas road tar is obtained by the destructive distillation of coal or wood. Both bitumen and tar have similar appearance, black in color through they have different characteristics. In this study VG 30 grade of bitumen is used as a binder. Various test results as shown in table 1 .

\subsection{Aggregates:-}

Aggregates is a collection of mineral materials like sand, gravel and crushed stone that are used with binding medium such as water, bitumen, Portland cement, lime to produced compound materials like that bitumen concrete and Portland cement concrete. Prime ingredients of pavement construction are aggregates. The aggregate should have good and sufficient Strength, Hardness, Toughness, Crushed Aggregate produced higher Stability. In this study crushed basalt aggregates of $10 \mathrm{~mm}, 6 \mathrm{~mm}$ nominal size and crusher dust was used. Various test results observed on aggregates shown in table 2.

\subsection{Filler:-}

Aggregate passing through $0.075 \mathrm{~mm}$ IS sieve is called as filler. In bitumen mixes there is different type of fillers were used like limestone dust, cement, stone dust, brick dust, silica fume or marble dust cement, fly ash and Stone dust are used as filler. Function of filler is to fill up the voids in the mixes. By using of Filler in the bitumen mixes can makes the bitumen more harder and stiffer. This will cause least possible of deformation occurs due to the traffic load. The filler which used in design of bitumen mixes always free from organic impurities. In this study lime is used as filler. The specific gravity of lime found out to be 2.4 .

\subsection{Aggregates Gradation:-}

Gradation of aggregates is a important factor which affecting permanent deformation of hot mix asphalt. Aggregate grading and binder content when tested in accordance with IS:2386 Part 1 the combined grading of the coarse and fine aggregate and added filler shall fall within the limits as shown in table. The combined gradation range for the different size of aggregates as specified in MoRTH for SDBC mix is present in table 3 .

Table 1.

\begin{tabular}{|l|l|l|l|l|}
\hline S.N & Description of Test & Specification as per IS: 73 (2007) & Test Method & Test result \\
\hline 1 & Penetration Value of bitumen & $50-70 \mathrm{~mm}$ & IS-1203 & $62.5 \mathrm{~mm}$ \\
\hline 2 & Ductility & Min. $40 \mathrm{~cm}$ & IS-1208 & $90.4 \mathrm{~cm}$ \\
\hline 3 & Specific Gravity & Min. 0.99 & IS-1202 & 1.025 \\
\hline 4 & Softening Point & $>47^{\circ} \mathrm{C}$ & IS-1205 & $56^{\circ} \mathrm{C}$ \\
\hline 5 & Viscosity at $135^{\circ} \mathrm{C}$ & Min. $350 \mathrm{cSt}$ & IS-1206 & $380 \mathrm{cSt}$ \\
\hline
\end{tabular}

Table 2.

\begin{tabular}{|c|c|c|c|c|}
\hline S.NO. & Description of Test & Specification as per MORTH table-500-18 & Test Method & Test result \\
\hline 1 & Aggregate Crushing value (\%) & Max $10-25$ & IS-2386 (P IV) & $14.48 \%$ \\
\hline 2 & Aggregate Impact value (\%) & $\operatorname{Max} 24 \%$ & IS-2386 (P IV) & $17.9 \%$ \\
\hline 3 & Loss Angles Abrasion (\%) & $\operatorname{Max} 30 \%$ & IS-2386 (P IV) & $22.08 \%$ \\
\hline 4 & Water Absorption & $\operatorname{Max} 2 \%$ & IS-2386 (P III) & $0.65 \%$ \\
\hline 5 & $\begin{array}{l}\text { Specific gravity } \\
10 \mathrm{~mm} \\
6 \mathrm{~mm} \\
\text { Dust } \\
\text { Lime }\end{array}$ & $2.5-3.0$ & - & $\begin{array}{l}2.67 \\
2.72 \\
2.78 \\
2.4 \\
\end{array}$ \\
\hline 6 & Stripping & Min. retained coating $95 \%$ & IS-6241-1971 & $97 \%$ \\
\hline
\end{tabular}


Table 3.

\begin{tabular}{|l|l|l|}
\hline Grading & 1 & 2 \\
\hline $\begin{array}{l}\text { Nominal } \\
\text { aggregate size }\end{array}$ & $19 \mathrm{~mm}$ & $13 \mathrm{~mm}$ \\
\hline $\begin{array}{l}\text { Layer } \\
\text { Thickness }\end{array}$ & $50-65 \mathrm{~mm}$ & $30-45 \mathrm{~mm}$ \\
\hline & $\begin{array}{l}\text { Cumulative } \\
\text { aggregate passing } \\
\%\end{array}$ & $\begin{array}{l}\text { Cumulative } \\
\text { aggregate passing }\end{array}$ \\
IS Sieve(mm) & - & - \\
\hline $\begin{array}{l}45 \\
37.5\end{array}$ & - & - \\
26.5 & 100 & - \\
19 & $79-100$ & - \\
13.2 & $59-79$ & 100 \\
9.5 & $52-72$ & $90-100$ \\
4.75 & $35-55$ & $35-51$ \\
2.36 & $28-44$ & $24-39$ \\
1.18 & $20-34$ & $15-30$ \\
0.6 & $15-27$ & - \\
0.3 & $10-20$ & $9-19$ \\
0.15 & $5-13$ & - \\
0.075 & $2-8$ & $3-8$ \\
\hline $\begin{array}{l}\text { Bitumen } \\
\text { content \% by } \\
\text { mass of total } \\
\text { mix }\end{array}$ & $5.00-6.00$ & $5.00-7.00$ \\
\hline $\begin{array}{l}\text { Bitumen grade } \\
\text { (pen.) }\end{array}$ & 65 & \\
\hline
\end{tabular}

In this study the grading 2 was selected, nominal aggregate size is $13 \mathrm{~mm}$ for layer thickness $30-45 \mathrm{~mm}$. Then gradation range divided into five grades Lower Grade (LG), Lower Middle Grade (LMG), Middle Grade (MG), Higher Middle Grade (HMG), and Higher Grade (HG) shown in table 4 and fig 1 .

Table 4.

\begin{tabular}{|l|l|l|l|l|l|l|}
\hline $\begin{array}{l}\text { Sieve } \\
\text { size }\end{array}$ & L.G & L.M.G & M.G & H.M.G & H.G. & MoRTH \\
\hline $\begin{array}{l}9.5 \\
\mathrm{~mm}\end{array}$ & 90 & 92.5 & 95 & 97.5 & 100 & $90-10$ \\
\hline $\begin{array}{l}4.75 \\
\mathrm{~mm}\end{array}$ & 35 & 39 & 43 & 47 & 51 & $35-51$ \\
\hline $\begin{array}{l}2.36 \\
\mathrm{~mm}\end{array}$ & 24 & 27.75 & 31.5 & 35 & 39 & $24-39$ \\
\hline $\begin{array}{l}1.18 \\
\mathrm{~mm}\end{array}$ & 15 & 18.75 & 22.5 & 26 & 30 & $15-30$ \\
\hline $\begin{array}{l}0.30 \\
\mathrm{~mm}\end{array}$ & 9 & 11.5 & 14 & 16.5 & 19 & $9-19$ \\
\hline $\begin{array}{l}0.075 \\
\mathrm{~mm}\end{array}$ & 3 & 4.25 & 5.5 & 6.75 & 8 & $3-8$ \\
\hline
\end{tabular}

\section{Gradation curve}

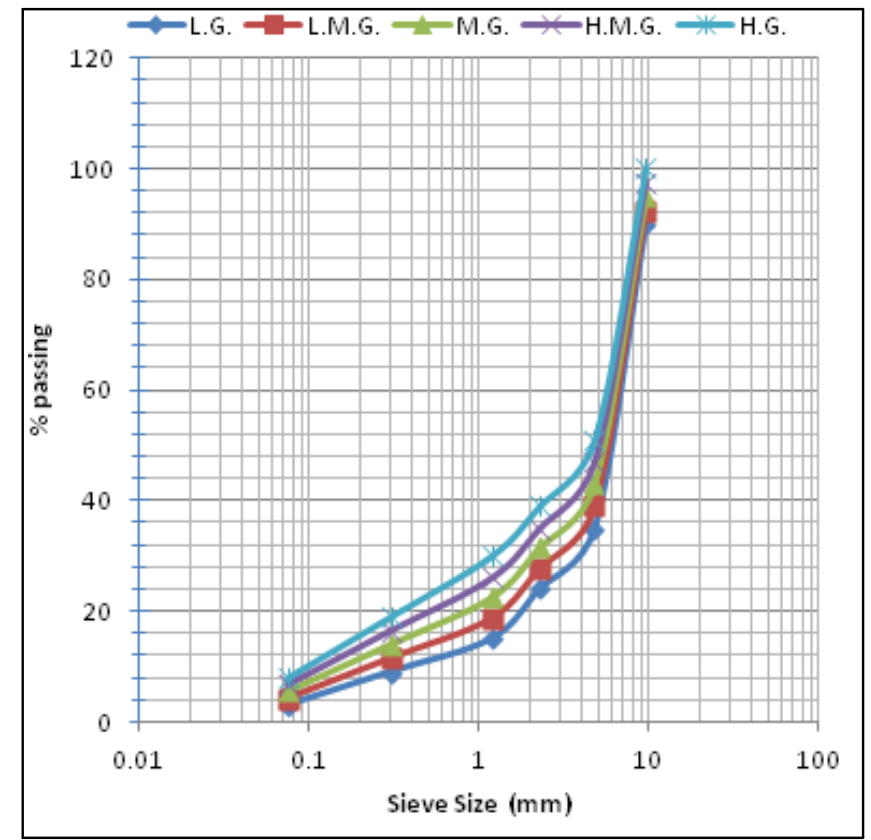

Fig 1. Gradation curve for different -different sieve size

\section{RESULTS AND DISCUSSIONS}

Marshall Parameters obtained as Stability, Flow, Density, Air voids, Voids filled with bitumen (VFB) for Lower Grade (L.G.), Lower Middle Grade (L.M.G.), Middle Grade (M.G.), Higher Middle Grade (H.M.G.), Higher Grade (H.G.) at $4.5 \%, 5 \%, 5.5 \%$ bitumen are shown in figures 2 to 6 .

\subsection{STABILITY}

According to MoRTH table 500-16 minimum Stability for Semi Dense Bituminous concrete pavements is $8.2 \mathrm{KN}$ at $60^{\circ} \mathrm{C}$. The stability values for all five gradations are much higher that of minimum value prescribed in guidelines. In this study it is observed that when bitumen percent is increased stability is also increased at certain point after increment of bitumen percent it again decreasing. Stability value is highest in M.G. and lowest in H.G. at $4.5 \%$ bitumen content. Stability value is highest in L.M.G. and lowest in H.G. at 5\% bitumen content. Stability value is highest in L.M.G. and lowest in H.G. at 5.5\% bitumen content. Shown in fig. 2.

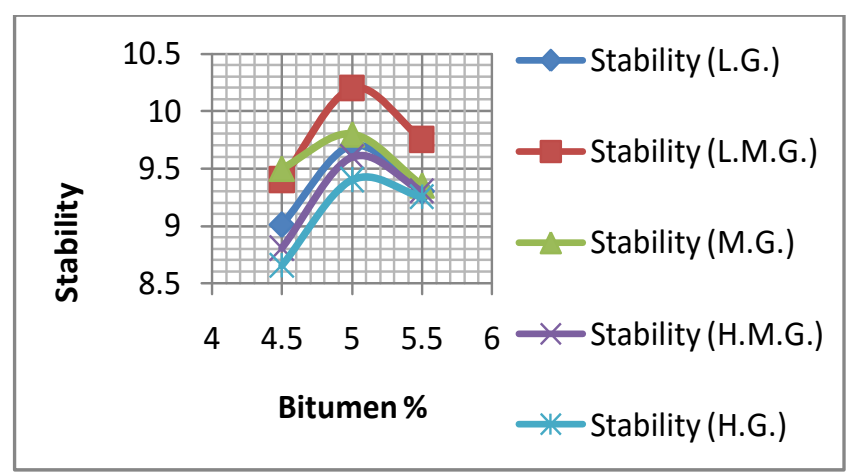

Fig 2. Variation of stability at different bitumen content 


\subsection{FLOW VALUES}

MoRTH specified the flow values in the range of 2 to $4 \mathrm{~mm}$ for S.D.B.C. mix. In this study for all gradations, the flow values are in this range. It is observed that due to increasing bitumen percent the flow value is also increasing. Flow value is highest in L.M.G. and lowest in H.G. at $4.5 \%$ bitumen content. Flow value is highest in M.G. and lowest in H.M.G. at $5 \%$ bitumen content. Flow value is highest in M.G. and lowest in H.M.G. at $5.5 \%$ bitumen content. Shown in fig 3.

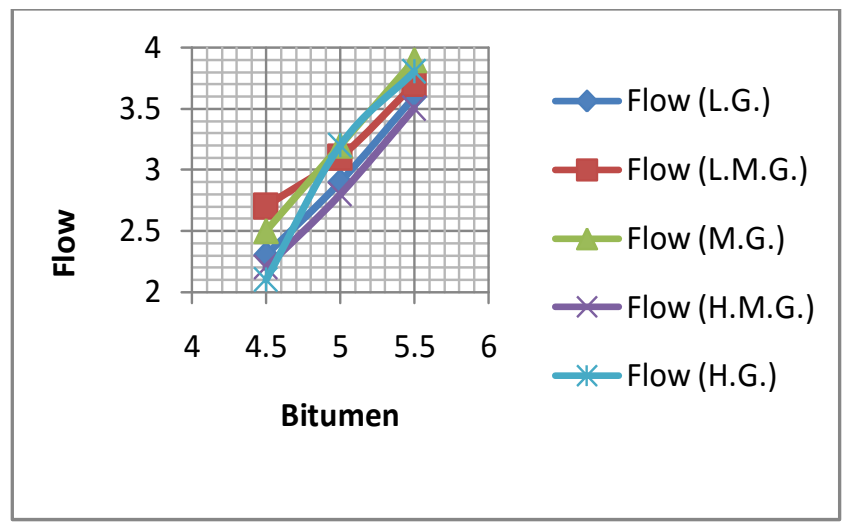

Fig 3. Variation of Flow at different bitumen content

\subsection{DENSITY}

In this study it is observed that when bitumen percent is increased Density is also increased at certain point after increment of bitumen percent it again decreasing. Density value is highest in L.M.G. and lowest in H.G. at $4.5 \%$ bitumen content. Density value is highest in L.M.G. and lowest in M.G. at 5\% bitumen content. Density value is highest in L.M.G. and lowest in M.G. at $5.5 \%$ bitumen content. Shown in fig 4.

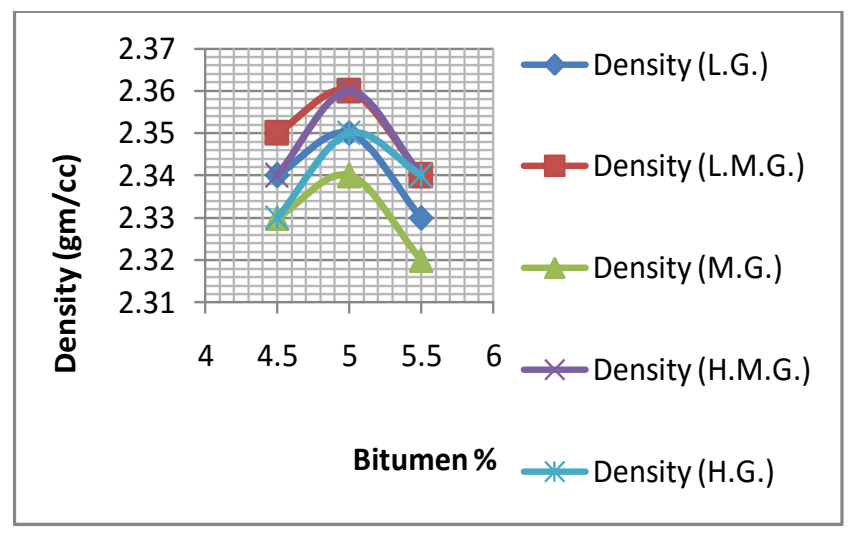

Fig 4

\subsection{AIR VOIDS, Vv}

The value of air voids in range of $3-5 \%$ is specified by MoRTH table 500-16. In this study for all gradations, the air voids percent are in this range. It is observed that at lower percent of bitumen air voids is higher, due to increasing of percent of bitumen the air voids percent are decreasing. Air voids is highest in L.M.G. and lowest in H.G. at $4.5 \%$ bitumen content. Air voids is highest in M.G. and lowest in
H.M.G. at 5\% bitumen content. Air voids is highest in M.G. and lowest in H.M.G. at 5.5\% bitumen content. Shown in fig 5.

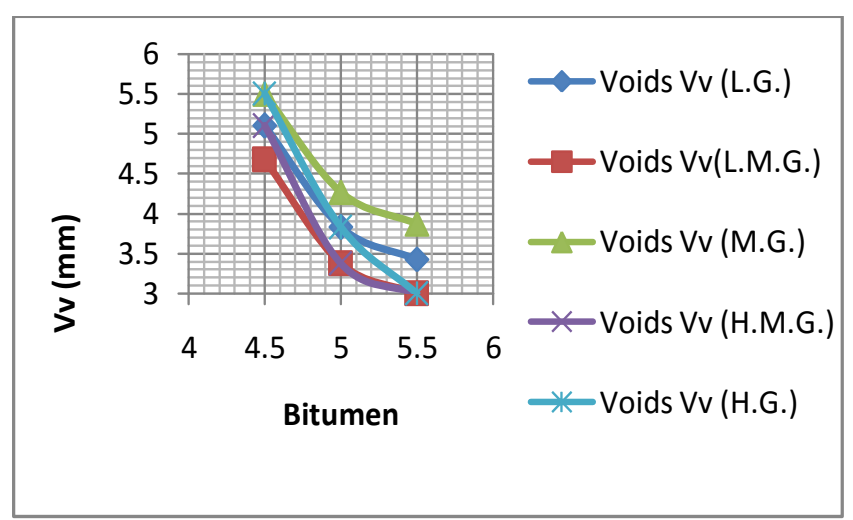

Fig 5. Variation of Air Voids at different bitumen content

\subsection{VOIDS FILLED WITH BITUMEN (V.F.B.)}

MoRTH specified the Voids filled with bitumen (V.F.B.) values in the range of 65 to $78 \%$ for S.D.B.C. mix. It is observed that for all gradations VFB values are in this specified range. This study observed that when the percent of bitumen is increasing then the value to V.F.B. is increasing for all gradation. V.F.B. value is highest in L.M.G. and lowest in H.G. at $4.5 \%$ bitumen content. V.F.B. value is highest in L.M.G. and lowest in M.G. at 5\% bitumen content. V.F.B. value is highest in L.M.G. and lowest in M.G. at 5.5\% bitumen content. Shown in fig 6 .

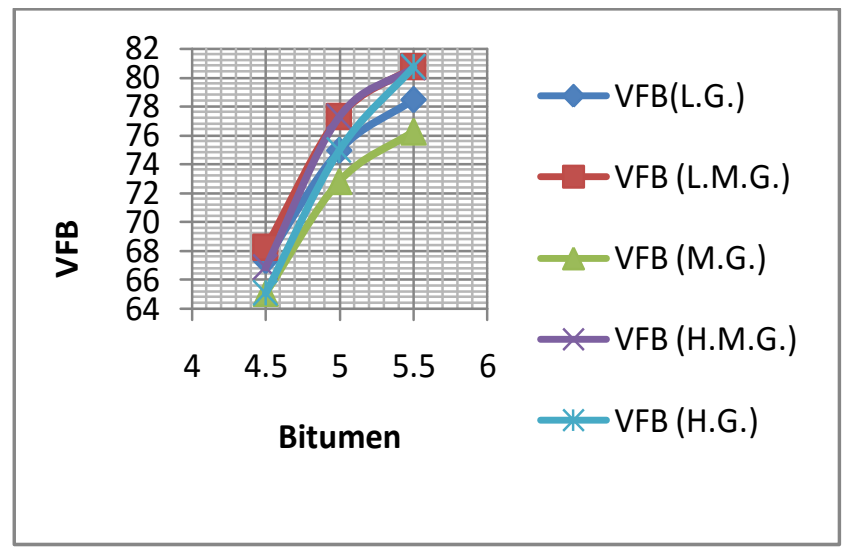

Fig 6: Variation of V.F.B. at different bitumen content

\section{Summary of Marshall Test:-}

At each gradation and aggregate type, Marshall test specimens of $101.6 \mathrm{~mm}$ dia. And $63.5 \mathrm{~mm}$ thick were prepared at $4.5 \%, 5 \%, 5.5 \%$ bitumen content to study the effect of aggregate gradation on the Marshall properties of SDBC mix. The optimum bitumen content (OBC), and other properties such as Stability, Bulk Density, Flow, Voids filled with bitumen (V.F.B.) and Air voids obtained at OBC were plotted against respective gradations shown in table 5 and fig. 7 to 12 . 
Table 5.

\begin{tabular}{|l|l|l|l|l|l|}
\hline Properties & L.G. & L.M.G. & M.G. & H.M.G. & H.G. \\
\hline O.B.C. \% & 4.97 & 4.9 & 5.1 & 4.93 & 4.98 \\
\hline $\begin{array}{l}\text { Stability, } \\
\text { kg }\end{array}$ & 9.65 & 10.1 & 9.75 & 9.56 & 9.36 \\
\hline Flow, mm & 2.8 & 3 & 3.3 & 2.7 & 3.2 \\
\hline Density & 2.347 & 2.344 & 2.338 & 2.345 & 2.349 \\
\hline V.F.B. & 74.5 & 76 & 74 & 76.5 & 74.2 \\
\hline $\begin{array}{l}\text { Air voids, } \\
\%\end{array}$ & 3.8 & 3.6 & 4.1 & 3.56 & 3.76 \\
\hline
\end{tabular}

\section{O.B.C.}

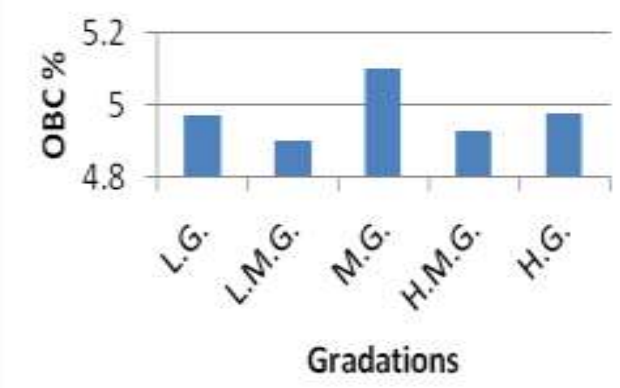

Fig 7. All Gradation vs O.B.C. variation

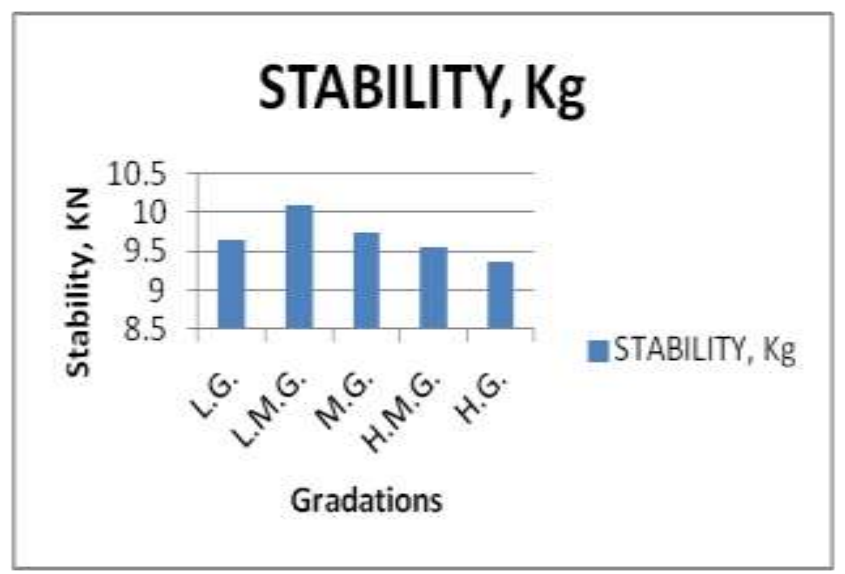

Fig 8. All Gradation vs Stability variation

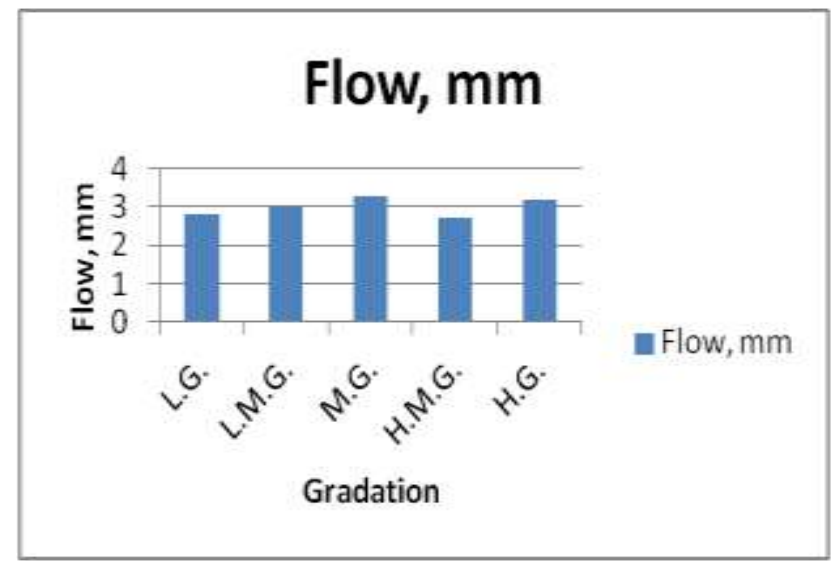

Fig 9. All Gradation vs Flow variation

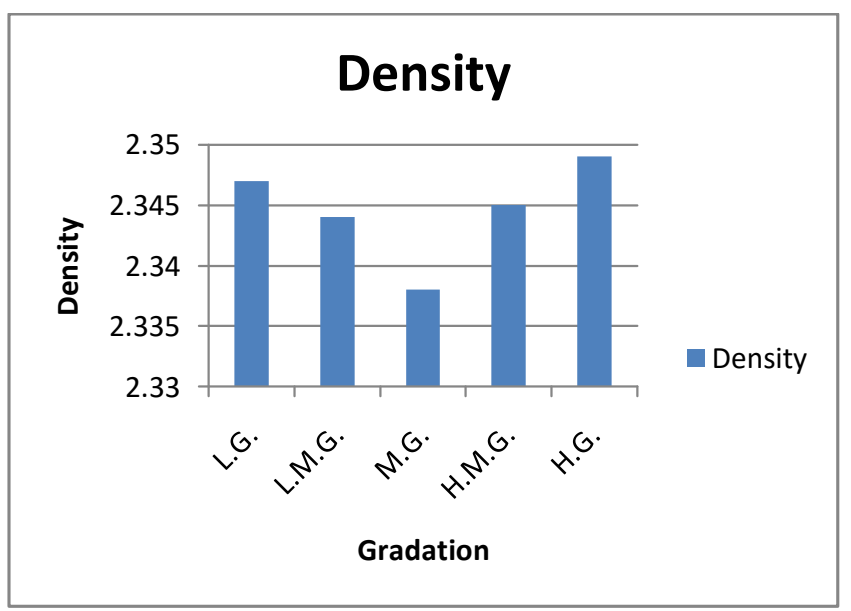

Fig 10. All Gradation vs Density variation

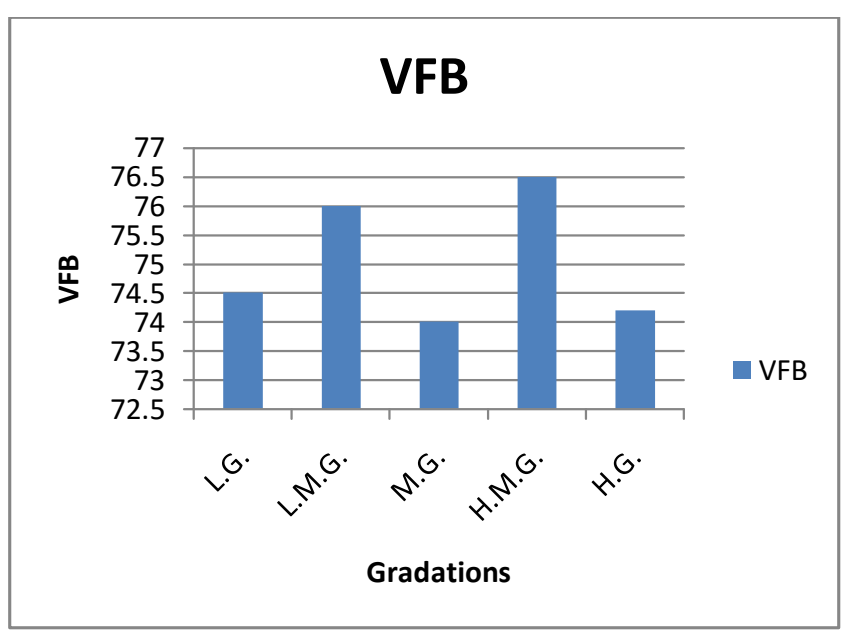

Fig 11. All Gradation vs V.F.B. variation

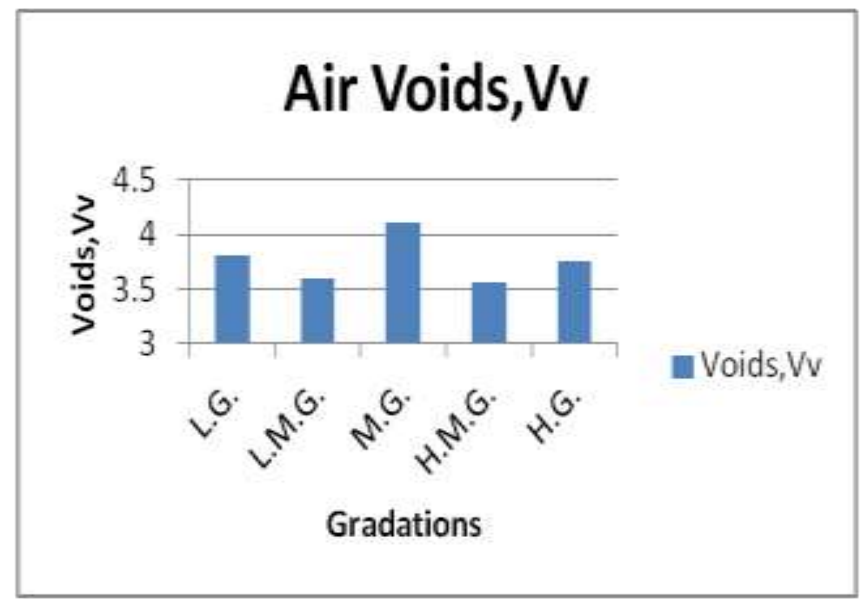

Fig 12. All Gradation vs Air voids

\section{CONCLUSIONS}

Based on the various laboratory tests the following results concluded that:-

1. The Optimum Binder Content (O.B.C.) is minimum in lower middle grade (L.M.G.) which is more economical.

2. Stability is also maximum in Lower Middle Grade (L.M.G.). 
3. Flow is highest in Middle Grade (M.G.) and minimum is at Higher Middle Grade (H.M.G.).

4. The density is highest in Lower Grade (L.G.) and lowest in Middle Grade (M.G.)

5. V.F.B. is highest at Higher Middle Grade (H.M.G.) and lower middle grade (L.M.G), lowest in middle grade (M.G.)

6. Air voids highest in Middle Grade (M.G.) and lowest in Higher Middle Grade (H.M.G.).

Based on the observations it concluded that the conventional practice of designing semi dense bituminous concrete mixes at mid point gradation does not result in the best mix. The other Marshall properties are not superior at mid point gradation. From the above points it can be concluded that in the design of S.D.B.C. mix most of the Marshall properties are superior at Lower Middle gradation of MoRTH specifications.

\section{REFERENCES}

[1]. Ministry of Roads Transport and Highways (MoRTH) 2013,Specifications for Road and Bridges works, Fifth Revision, Indian Road Congress, New Delhi.

[2]. Banerji A.K. and Das A. (2014) "Influence of Variation in the Aggregate Gradation Range on Mix Design Properties of Bituminous Concrete mixes used as Wearing Course " International Journal of Engineering Research \& Technology (IJERT), Vol. 3, September- 2014.

[3]. Afaf A.H.M. (2014) "Effect of gradation and type on hot asphalt concrete mix properties "Journal of Engineering Science Assiut University Faculty of Engineering, Vol. 42 No.3

May 2014 Pages: 567-574.

[5].Sarika P., Sandra A.K. (2015) "Comparing properties of bituminous concrete mixes prepared using Morth and super pave gradations" International Journal of Engineering Research \& Technology (IJERT), Vol. 04, Feb-2015.

[6]. Ahlrich, R.C.(1996), "Influence of aggregate gradation and Particle shape/Texture on Permanent Deformation of Hot Mix Asphalt Pavements", Army Engineer Waterways Experiment Station Vicksburg MS Geotechnical Lab.

[7]. Roberts, F. L., Kandhal, P. S., Brown, E. R., Lee, D., and Kennedy, T., (1996), "Hot Mix Asphalt Materials, Mixtures Design, and Construction" NAPA Education Foundation, Lanham, Maryland. First Edition, pp. 241-250.

[8]. C.E.G. Justo et al. (2009), "Highway Materials \& Pavement Testing" Nem chand \& Bros Roorkee, India.

[9]. Joseph J.V (2015)." To Determine Impact of Shape of Course Aggregate on DBM Mix" International Journal of Engineering Research, Volume No.4, Issue No.4, pp : 203205

[10]. Anjum M.I.(2013) "Aggregates Sustainability Through Preparation Of Bituminous Mixes At Combined Gradation:" International Journal of Research in Engineering and Technology, Volume: 02 Issue: 12, Dec-2013. 